\title{
Duloxetine-Induced Liver Injury in Patients with Major Depressive Disorder
}

\author{
Seung-Gul Kang ${ }^{1}$, Young-Min Park ${ }^{2}$, Heon-Jeong Lee ${ }^{3}$ and Byungmun Yoon ${ }^{4}$ \\ ${ }^{1}$ Department of Psychiatry, Catholic University of Daegu School of Medicine, Daegu, Korea \\ ${ }^{2}$ Department of Neuropsychiatry, Ilsan Paik Hospital, Inje University College of Medicine, Goyang, Korea \\ ${ }^{3}$ Department of Psychiatry, Korea University College of Medicine, Seoul, Korea \\ ${ }^{4}$ Department of Psychiatry, Maumtomaum Clinic, Yongin, Korea
}

Duloxetine is a balanced serotonin-norepinephrine reuptake inhibitor. Duloxetine-induced liver injury in patients with preexisting liver disease or chronic alcohol use is known. However, we have found that duloxetine can also induce liver injury in cases without those risk factors. We recommend that clinicians should monitor liver function carefully following duloxetine treatment.

Psychiatry Investig 2011;8:269-271

Key Words Duloxetine, Liver injury, Major depressive disorder.

\section{INTRODUCTION}

Drug-induced liver injury (DILI) is a term that describes abnormalities in liver function tests (LFTs) that are attributable to medication intake. ${ }^{1}$ DILI accounts for more than $50 \%$ of acute liver failures and is the most common cause of the withdrawal of drugs from the pharmaceutical market. ${ }^{2,3}$

Eli Lilly and Company informed healthcare professionals that there had been some postmarketing reports of cholestatic jaundice and hepatitis in patients with chronic liver disease or cirrhosis receiving duloxetine in late 2005. In addition, the product labeling was modified by stating that duloxetine should not ordinarily be prescribed to patients with chronic alcohol use or evidence of chronic liver disease.

Duloxetine was approved in Korea for major depressive disorder (MDD), generalized anxiety disorder, and diabetic peripheral neuropathic pain (DPNP) in 2009. It is a balanced and potent serotonin-norepinephrine reuptake inhibitor, and has been prescribed increasingly in Korea. However, data regard-

Received: January 19, 2011 Revised: May 8, 2011

Accepted: May 8, 2011 Available online: August 10, 2011

$\triangle$ Correspondence: Young-Min Park, MD, PhD

Department of Neuropsychiatry, Ilsan Paik Hospital, Inje University College of Medicine, 2240 Daehwa-dong, Ilsansu-ku, Goyang 411-706, Korea

Tel: +82-31-910-7260, Fax: +82-31-910-7268, E-mail: medipark@hanmail.net

(a) This is an Open Access article distributed under the terms of the Creative Commons Attribution Non-Commercial License (http://creativecommons.org/licenses/bync/3.0) which permits unrestricted non-commercial use, distribution, and reproduction in any medium, provided the original work is properly cited. ing its effects on the liver are not well known in this country. We have previously reported a case of duloxetine-induced liver injury in a patient with MDD. ${ }^{4}$

We have now experienced another three cases involving duloxetine-induced liver injury. Thus, we describe herein a case series of liver injury in patients with MDD. A MEDLINE search revealed no other report related to duloxetine-induced liver injury in Asian patients; this therefore appears to be the first reported case thereof in Asia.

\section{CASES}

\section{Case 1}

A 22-year-old Korean male visited our clinic due to depression. The patient had no relevant medical history and no history of substance abuse; his laboratory tests were also normal. He was diagnosed with MDD, and initially treated with duloxetine at $30 \mathrm{mg} /$ day. After 3 weeks, the dosage was increased to $60 \mathrm{mg} /$ day. However, the patient had only a partial response and complained of fatigue. Laboratory tests were performed, and his total bilirubin was $1.8 \mathrm{mg} / \mathrm{dL}$ and alanine transaminase (ALT) was $60 \mathrm{U} / \mathrm{L}$ (See Table 1 for normal range in our hospital). Thus, duloxetine was immediately discontinued and replaced by escitalopram. Liver function had normalized by 4 months after the discontinuation of duloxetine, at which time the patient's total bilirubin and ALT levels were $1.2 \mathrm{mg} / \mathrm{dL}$ and $7 \mathrm{U} / \mathrm{L}$, respectively. 
Table 1. Normal ranges of LFT parameters in our hospital laboratory

\begin{tabular}{lc}
\hline LFT & Normal range \\
\hline Protein & $6.6-8.3 \mathrm{~g} / \mathrm{dL}$ \\
Albumin & $3.5-5.2 \mathrm{~g} / \mathrm{dL}$ \\
Total bilirubin & $0.2-1.3 \mathrm{mg} / \mathrm{dL}$ \\
ALT & $<40 \mathrm{U} / \mathrm{L}$ \\
AST & $<40 \mathrm{U} / \mathrm{L}$ \\
Amylase & $22-85 \mathrm{U} / \mathrm{L}$ \\
\hline
\end{tabular}

LFT: liver function test, ALT: alanine transaminase, AST: aspartate transaminase

\section{Case 2}

A 65-year-old Korean female with a 6-month history of MDD was admitted to our hospital. She had attempted suicide by taking $5 \mathrm{mg}$ of clonazepam (ten tablets) before her arrival at the emergency room. Fortunately, the patient's laboratory findings were near normal at that time. The results of LFTs were as follows (See Table 1 for normal range): total protein, $6.5 \mathrm{~g} / \mathrm{dL}$; albumin, $3.2 \mathrm{~g} / \mathrm{dL}$; total bilirubin, $1.5 \mathrm{mg} / \mathrm{dL}$; ALT, 9 $\mathrm{U} / \mathrm{L}$; aspartate transaminase (AST), $17 \mathrm{U} / \mathrm{L}$; amylase, $75 \mathrm{U} / \mathrm{L}$; hepatitis B virus surface antigen (HBs Ag), positive; and hepatitis $B$ virus surface antibody, negative. This patient was initially treated from 2 days after admission with duloxetine at 30 $\mathrm{mg} /$ day; after 4 days, the dosage increased to $60 \mathrm{mg} /$ day. LFTs were repeated 1 week after the commencement of duloxetine treatment. Although the patient's clinical status improved, the results of her LFTs were aggravated: total protein, $5.4 \mathrm{~g} / \mathrm{dL}$; albumin, $3.0 \mathrm{~g} / \mathrm{dL}$; total bilirubin, $0.9 \mathrm{mg} / \mathrm{dL}$; ALT, $52 \mathrm{U} / \mathrm{L}$; AST, $43 \mathrm{U} / \mathrm{L}$; and amylase, $101 \mathrm{U} / \mathrm{L}$. Duloxetine was thought to be responsible for this deterioration of liver function, and so was discontinued immediately and replaced by mirtazapine. One week following duloxetine discontinuation, LFTs were once again repeated and were found to have improved: total protein, $6.6 \mathrm{~g} / \mathrm{dL}$; albumin, $3.6 \mathrm{~g} / \mathrm{dL}$; total bilirubin, $0.9 \mathrm{mg} / \mathrm{dL}$; ALT, 31 U/L; AST, 27 U/L; and amylase, 104 U/L.

\section{Case 3}

A 37-year-old Korean male with MDD was admitted to our department in July 2009. This patient had been involved in a traffic accident in December 2008, in which he had suffered an epidural hematoma and facial bone fracture. He submitted to corrective surgery in the Department of Neurosurgery and was medicated with valproate to prevent seizures. In April 2009 he was referred to our department because of depression, at which time venlafaxine and quetiapine were added to the valproate. Thus, between April and July 2009 the patient had been continually medicated with venlafaxine at $75 \mathrm{mg} /$ day, quetiapine at $400 \mathrm{mg} /$ day, and valproate at $1,200 \mathrm{mg}$ /day. After July 2009, venlafaxine was replaced by duloxetine due to the persistence of depression. Laboratory findings including LFTs were normal before duloxetine treatment: total protein, $7.2 \mathrm{~g} / \mathrm{dL}$; albumin, $3.9 \mathrm{~g} / \mathrm{dL}$; total bilirubin, $0.3 \mathrm{mg} / \mathrm{dL}$; ALT, $22 \mathrm{U} / \mathrm{L} ;$ and AST, $14 \mathrm{U} / \mathrm{L}$.

After discharge, the patient was maintained on quetiapine (400 mg/day), duloxetine ( $60 \mathrm{mg} /$ day), and valproate $(900 \mathrm{mg} /$ day) combination therapy for 5 months, after which LFTs were repeated. Although he did not complain of any symptoms, the patient's ALT and AST levels had increased to $69 \mathrm{U} / \mathrm{L}$ and 42 $\mathrm{U} / \mathrm{L}$, respectively, while the other LFT parameters were within normal limits. The patient was observed for a further 3 months without changing medication, and then the LFTs were repeated; ALT and AST levels further aggravated to $197 \mathrm{U} / \mathrm{L}$ and 93 U/L, respectively. Duloxetine was therefore discontinued immediately.

\section{DISCUSSION}

Some clinical studies have found a relationship between liver injury and medication with duloxetine. In patients with a normal baseline ALT, both ALT and AST values peaked after 8 weeks of duloxetine medication, and alkaline phosphatase (ALP) steadily increased to a maximum value at 52 weeks. ${ }^{5}$ We previously reported the jaundice after duloxetine treatment in a healthy young adult without preexisting risk factors. ${ }^{4}$

All of our cases were medicated with duloxetine at a high dosage $(60 \mathrm{mg} /$ day). In an analysis that included postapproval trials, the ALT level was higher than three times the upper limit of normal (ULN) in approximately $1 \%$ of duloxetine-treated patients; there is evidence that these elevations of ALT and AST are dose dependent. ${ }^{6}$ Duloxetine treatment for DPNP was associated with a significant increase in ALP levels. ${ }^{7}$ In particular, the high-dosage group exhibited a significant increase in $\gamma$-glutamyl transferase. In a published case, hepatic failure occurred 6 weeks after the daily dose was increased from 30 to $60 \mathrm{mg} .{ }^{8}$

The US FDA defines DILI as a persistent elevation of at least three times the ULN in ALT levels accompanied by jaundice (total bilirubin greater than or equal to twice the ULN). ${ }^{9}$ Based on this definition, two of our cases (1 and 2) are not authentic DILI. However, in case 1 the elevation of ALT was accompanied by an elevation of total bilirubin, and in case 2 the elevation of ALT was accompanied by the aggravation of protein, albumin, and amylase. In case 2 the abnormal LFT findings were detected early (1 week after duloxetine treatment) and duloxetine medication ceased immediately. Otherwise, severe DILI might have developed in this case.

Our cases have a temporal relationship between duloxetine treatment and DILI. In case 1 the patient was a young and healthy adult without medical or substance abuse history. Th- 
erefore, the cause of DILI could be attributed to duloxetine. In contrast, in case 2 the patient had attempted suicide by taking clonazepam, intoxication with which might be the cause of DILI. However, the LFTs findings after clonazepam overdose were normal and her liver function was aggravated only after duloxetine treatment; discontinuation thereof normalized her liver function. Valproate is also known to cause DILI. However, the liver function of case 3 , who was medicated continuously for several months with valproate, venlafaxine, and quetiapine was normal. DILI developed only after venlafaxine was replaced by duloxetine. It is therefore probable that duloxetine alone was responsible for the DILI, or at the very least, a synergic effect of valproate and duloxetine caused his DILI.

Individuals with preexisting chronic liver disease or excessive alcohol consumption are at a greater risk of duloxetine-induced liver injury. ${ }^{10}$ However, our cases did not have those risk factors. Regarding case 2, she was positive for HBs Ag. Thus, it is suggested that clinicians should monitor liver function carefully after duloxetine treatment in patients with HBs Ag.

It may be concluded that the administration of duloxetine can induce liver injury in patients with MDD. Although the mechanism underlying the observed liver injury in these cases remains unclear, clinicians should monitor liver function carefully during duloxetine treatment. Further investigations with larger samples are needed.

\section{Acknowledgments}

This study was supported by a grant from National Research Foundation of Korea (NRF) (No. 431-2010-1-E00027).

\section{REFERENCES}

1. Bleibel W, Kim S, D'Silva K, Lemmer ER. Drug-induced liver injury: review article. Dig Dis Sci 2007;52:2463-2471.

2. Ostapowicz G, Fontana RJ, Schiødt FV, Larson A, Davern TJ, Han SH, et al. Results of a prospective study of acute liver failure at 17 tertiary care centers in the United States. Ann Intern Med 2002;137:947-954.

3. Temple RJ, Himmel MH. Safety of newly approved drugs: implications for prescribing. JAMA 2002;287:2273-2275.

4. Park YM, Lee BH, Lee HJ, Kang SG. Cholestatic jaundice induced by duloxetine in a patient with major depressive disorder. Psychiatry Investig 2010;7:228-230.

5. Wernicke J, Pangallo B, Wang F, Murray I, Henck JW, Knadler MP, et al. Hepatic effects of duloxetine-I: non-clinical and clinical trial data. Curr Drug Saf 2008;3:132-142.

6. Hudson JI, Wohlreich MM, Kajdasz DK, Mallinckrodt CH, Watkin JG, Martynov OV. Safety and tolerability of duloxetine in the treatment of major depressive disorder: analysis of pooled data from eight placebo-controlled clinical trials. Hum Psychopharmacol 2005;20:327-341.

7. Raskin J, Wang F, Pritchett YL, Goldstein DJ. Duloxetine for patients with diabetic peripheral neuropathic pain: a 6-month open-label safety study. Pain Med 2006;7:373-385.

8. Hanje AJ, Pell LJ, Votolato NA, Frankel WL, Kirkpatrick RB. Case report: fulminant hepatic failure involving duloxetine hydrochloride. Clin Gastroenterol Hepatol 2006;4:912-917.

9. Holt MP, Ju C. Mechanisms of drug-induced liver injury. AAPS J 2006; 8:E48-E54.

10. McIntyre RS, Panjwani ZD, Nguyen HT, Woldeyohannes HO, Alsuwaidan M, Soczynska JK, et al. The hepatic safety profile of duloxetine: a review. Expert Opin Drug Metab Toxicol 2008;4:281-285. 